\title{
Preparation of a novel nano-scale lead (II) zigzag metal-organic coordination polymer with ultrasonic assistance: Synthesis, crystal structure, thermal properties and $\mathrm{NBO}$ analysis of $\left[\mathrm{Pb}(\mu-2-\mathrm{pinh})\left(\mathrm{N}_{3}\right) \mathrm{OH}_{2}\right]_{\mathrm{n}}$
}

\author{
Babak Mirtamizdoust, ${ }^{[a], *}$ Dariusz C. Bieńko, ${ }^{[b]}$ Younes Hanifehpour, ${ }^{[c]}$ \\ Edward R. T. Tiekink, ${ }^{[\mathrm{d}]}$ Veysel T. Yilmaz, ${ }^{[\mathrm{e}]}$ and Pejman Talemi ${ }^{[\mathrm{f}]}$ Sang \\ Woo Joo, ${ }^{[\mathrm{c}]}$
}

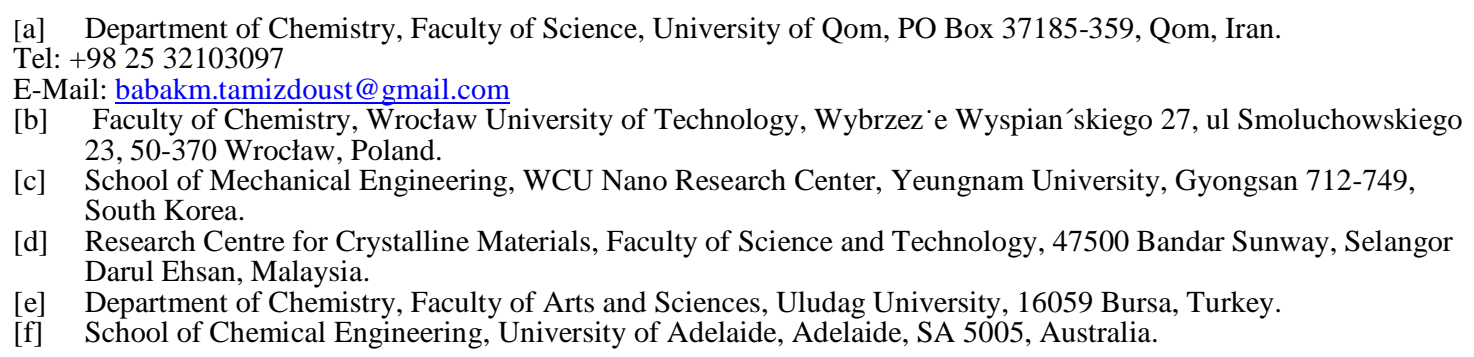

\begin{abstract}
A novel nano, cauliflower-shaped lead(II) metal-organic coordination polymer, $[\mathrm{Pb}(\mu-2-$ pinh) $\left.\left(\mathrm{N}_{3}\right) \mathrm{OH}_{2}\right]_{\mathrm{n}}(\mathbf{1})$, was synthesized using an ultrasonic method. The nanostructure was characterized by scanning electron microscopy (SEM), X-ray powder diffraction, IR spectroscopy, elemental analysis and thermal analysis. The compound was structurally characterized by single-crystal X-ray diffraction and takes the form of a zigzag onedimensional polymer in the solid-state. The coordination number of the lead(II) ions is six $\left(\mathrm{PbN}_{4} \mathrm{O}_{2}\right)$, with one oxygen and three nitrogen donor atoms derived from two linker organic ligands, one nitrogen atom from a terminal azide anion and one oxygen from coordinated water. It has a stereochemically active lone electron pair, and the coordination sphere is hemidirected. The zigzag 1D chains interact with neighbouring chains through weak interactions, creating a 3D supramolecular metal-organic framework. Lead oxide nanoparticles were obtained by thermolysis of the new nano coordination compound at $180{ }^{\circ} \mathrm{C}$ with oleic acid as a surfactant. The morphology and size were further studied using SEM. Natural bond orbital (NBO) analyses demonstrate the electronic properties of the lead centre and other atoms.
\end{abstract}

Keywords: Nano zigzag polymer, Nano, metal-organic coordination compound, NBO analysis, Lead(II) oxide nanoparticle 


\section{Introduction}

Recently, metal-organic coordination polymers have attracted interest due to their diverse structural motifs and useful potential properties [1,2]. Numerous factors affect the assembly of these coordination polymers, such as the coordination configuration of metal ions, geometric characteristics of organic ligand spacers, metal-ligand ratios, solvents, counter-anion characteristics and reaction conditions [3-7]. Because of their economic, environmental and biological roles, the selective sensing and chelation of toxic heavy metals such as $\mathrm{Pb}(\mathrm{II}), \mathrm{Cd}(\mathrm{II})$, and $\mathrm{Hg}(\mathrm{II})$ is very important. Lead is still the most commonly encountered toxic metal pollutant in the environment. The unique coordination chemistry of $\mathrm{Pb}$ (II) can be exploited to develop practical ligands as extractants, lead-poisoning treatments and sensors [8-10].

The chemistry of lead(II) coordination frameworks has attracted great interest because of its large ion radius, variable coordination number, the possibility of a stereochemically active lone pair of $6 \mathrm{~s}^{2}$ outer electrons, novel network topologies and other interesting properties [11]. Lead(II) has an electronic structure of $[\mathrm{Xe}] 4 \mathrm{f}^{14} 5 \mathrm{~d}^{10} 6 \mathrm{~s}^{2}$. The $6 \mathrm{~s}$ orbital contracts and stabilizes due to relativistic effects that are strongest in $\mathrm{Au}(\mathrm{I})$ but also occur in close $6 p$ metals $\{$ the meaning of the phrase is not clear: closed-6p shell? $\}$ such as lead. This stabilized 6s pair sometimes becomes an "inert pair," which explains why inorganic lead forms compounds in a lower oxidation state (less by two) than expected from its group number $[12,13]$. This may also influence the stereochemistry of lead(II)-organic coordination compounds.

This influence can be understood in terms of simple hybridization or valence shell electron-pair repulsion [14]. In spite of its stabilization, it seems that the 6s orbital can hybridize with the $6 p$ orbitals to give a "stereochemically active" 6s electron pair (or Stereochemically Active Lone Electron Pair (SALEP)), which occupies one position in the coordination sphere of the metal. Considering that the pair is not directly detectable, its presence is normally identified by a void in the distribution of the coordination bonds (hemidirected coordination; see scheme 1). In the absence of hybridization, the pair exhibits only $s$ character, which makes it "stereochemically inactive." Thus, the complex 
does not show a gap or void in the bond distribution (holodirected coordination; see Scheme 1) [12].

Scheme 1

In contrast to the usual hybrid metal-organic coordination compounds, there are very few reports on the synthesis of nano, metal-organic coordination polymers. Another application that has not yet been investigated thoroughly is the use of organic-inorganic coordination polymers as precursors for the preparation of inorganic nano compounds $[15,16]$. Theoretical methods such as DFT calculations can be used to find energy minima, determine structures and predict the spectroscopic and electronic properties of the compounds, and the results can be compared with experimental data for verification [18-21]. Despite this, there are only a few reports on theoretical calculations for the properties of lead(II) complexes.

Our research group has intensively focused on the synthesis and characterization of lead(II) complexes and their metal organic coordination polymers [22-35]. One of the tools that we have used in this work is sonochemistry, in which chemical reactions are influenced by the application of ultrasound $(20 \mathrm{KHz}$ to $10 \mathrm{MHz})$. The application of ultrasound in synthetic organic chemistry has received attention because ultrasonic waves in liquids cause chemical reactions in homogeneous and heterogeneous systems [17]. As a continuation of previous studies, we report the first synthesis of a lead(II) metal-organic coordination polymer, namely $\left[\mathrm{Pb}(\mu-2-\mathrm{pinh})\left(\mathrm{N}_{3}\right) \mathrm{OH}_{2}\right]_{\mathrm{n}}(\mathbf{1})$, which features a terminal azido ligand in the presence of the anion derived from the Schiff-base 2pyridinecarbaldehyde isonicotinoylhydrazone (H-2-pinh). We also report the first NBO analysis study of a lead(II)-azide complex and describe a convenient sonochemical synthesis for the preparation of (1) and its use in the preparation of $\mathrm{PbO}$ nanoparticles.

\section{Results and discussion}


The reaction between the H-2-pinh ligand with a solution of lead(II) acetate and sodium azide led to the formation of the new lead(II) coordination polymer, $[\mathrm{Pb}(\mu-2-$ pinh) $\left.\left(\mathrm{N}_{3}\right) \mathrm{OH}_{2}\right]_{\mathrm{n}}(\mathbf{1})$. Nano-cauliflower shapes of 1 were obtained by applying ultrasound to a methanolic solution containing the reagents, and single-crystalline materials were obtained by applying a heat gradient (the branched tube method [36]). There are very few reports on the synthesis of nano, cauliflower-shape compounds [52-54].

Scheme 2 gives an overview of the two different routes used for the synthesis of 1 :

\section{Scheme 2}

The elemental analysis and IR spectral results of the nanostructures and the singlecrystalline material are indistinguishable. The IR spectra of these species and calculated IR show the characteristic absorption bands of the 2-pinh anion (Fig. 1). The relatively weak band around $3064 \mathrm{~cm}^{-1}$ is attributed to the absorption of the aromatic $\mathrm{CH}$ hydrogen atoms. The absorption bands in the frequency range of 1499 to $1634 \mathrm{~cm}^{-1}$ corresponds to the vibrations of aromatic rings of the 2-pinh ligand. The absorption bands with strong intensity at $1460 \mathrm{~cm}^{-1}$ correspond to the $\mathrm{C}=\mathrm{N}$ bond of the imine group of the anion. The strong bands at $2021 \mathrm{~cm}^{-1}$ corresponds to $\mathrm{N}_{3}{ }^{-}$anions [37].

(Figure 1)

Fig. 2 shows the calculated PXRD from the crystallographic analysis (see below; Fig. 2a) and a comparison with the PXRD pattern of a typical sample of 1 prepared by the sonochemical process (Fig. 2b). Acceptable matches with small differences in $2 \theta$ values are noted. The significant broadening of the peaks (Fig. 2b) indicates the particles have nanometer dimensions. The size was estimated using the Scherrer formula, $D=$ $0.891 \lambda \beta \cos \theta$, where $\mathrm{D}$ is the average grain size, $\lambda$ the $\mathrm{X}$-ray wavelength $(0.15405 \mathrm{~nm})$, and $\theta$ and $\beta$ are the diffraction angle and full-width at half maximum of an observed peak, respectively. The average grain size was $30 \mathrm{~nm}$. Compound 1, prepared by the sonochemical method, shows an interesting morphology comprising sheet-like structures with an approximate thickness of $30 \mathrm{~nm}$ (Fig. 3). 
Figure 2

Figure 3

The formation mechanism of this structure needs further investigation. It may be a result of the packing of the crystal structure on a molecular level (see later; it is recommended that "later" be deleted - see comment below), which might have influenced the morphology. The single-crystal X-ray structure determination confirms that 1 has the stoichiometry $\left[\mathrm{Pb}(\mu-2-\text { pinh })\left(\mathrm{N}_{3}\right) \mathrm{OH}_{2}\right]_{\mathrm{n}}$. Fig. 4 shows the asymmetric unit and atom numbering scheme, while Table 1 presents the crystal data and structure refinement details.

Figure 4

\section{Table 1}

These data indicate that the lead atom is chelated by one oxygen and two nitrogen atoms of the 2-pinh anion. It is also coordinated by the pyridyl-N4 atom of a neighbouring molecule to generate a zigzag chain along the c-axis (Fig. 5a). Thus, the 2pinh ligand is tetradentate. The lead atom is also coordinated by N5 atom of a terminally bound azide and a water molecule. The water molecule and donor atoms from the 2-pinh ligands occupy an approximate plane with the azide N5 atom lying to one side. To the other side is a weakly connected N3 atom (3.283(5) $\AA$ ) that is otherwise not involved in the immediate coordination. This intermolecular interaction connects zigzag chains into double chains (Fig. 5b). As shown in Fig. 6, the lead atom is seven-coordinated, and a relatively large void is apparent on the same side of the $\mathrm{N}_{3} \mathrm{O}_{2}$ plane as the weakly bound N3 atom.

Figure 5

Figure 6 
Fig. 7 shows the unit cell contents. The double layers demonstrated in Fig. 5b stack along the a-axis and are connected in a three-dimensional architecture by $\mathrm{O} 1 \mathrm{w}-\mathrm{H}$...N3 hydrogen bonds. This indicates that this atom is pivotal in ensuring the cohesiveness of the crystal $\left(\mathrm{O} 1 \mathrm{w}-\mathrm{H} . . . \mathrm{N} 3^{\mathrm{iii}}=2.26 \AA\right.$; O1w...N $3^{\mathrm{iii}}=3.049(8) \AA$ and angle at $\mathrm{H} 1 \mathrm{w} 2=162^{\circ}$ for symmetry operation $1 / 2-\mathrm{x}, 1 / 2-\mathrm{y}, 1 / 2+\mathrm{z}$ ). The second water-bound hydrogen does not form a strong hydrogen bond but instead lies in the region defined by two terminal $\mathrm{N} 7$ atoms of the azide ligand [H...N7 $7^{\mathrm{iii}}=2.66 \AA$ and $\mathrm{H} . . . \mathrm{N} 7^{\mathrm{iv}}=2.76 \AA$ for iv: $\left.1 / 2+\mathrm{x}, 1 / 2-\mathrm{y}, 1-\mathrm{z}\right]$.

\section{Figure 7}

The gap or hole in the coordination geometry around the metal ions is likely occupied by a stereochemcially active lone pair of electrons on lead(II) [12], so the coordination geometry is based on a $\Psi$-dodecahedron. This possibility is supported by the observed shortening of the $\mathrm{Pb}-\mathrm{N}$ bonds on the side of the $\mathrm{Pb}^{2+}$ ion opposite to the putative lone pair, i.e. 2.347(6) $\AA$, compared with that, i.e. 3.283(5) $\AA$, adjacent to the lone pair [10]. \{Such an environment leaves space for close contact with another atom (Fig. 7). To find any other potential donor centre, it is necessary to extend the bonding limit. If a limit of $3.60 \AA$ is placed on the separation of $\mathrm{Pb}^{\mathrm{II}}$ from a donor atom, the next nearest contact, i.e. $\mathrm{Pb} \cdots \mathrm{N} 3^{\mathrm{i}}=3.511 \AA$ involves the 2-pinh ligand in a parallel chain - there is no such contact, the text is redundant and should simply be deleted $\}$. The $\mathrm{Pb} \cdots \mathrm{Pb}$ separation within the zigzag chain is 9.9731(6) $\AA$, and the $\mathrm{Pb} \cdots \mathrm{Pb}$ separation between loosely associated chains, Fig. 5b, is 5.3205(6) $\AA$, a distance still too long to be considered as significant.

\{ This section does not add to the understanding of the supramolecular association as this, as discussed above, is stabilised by the hydrogen bonding and intermolecular $\mathrm{Pb} \ldots \mathrm{N}$ interactions: I urge you to delete or reference to this as any interaction is encompased within a 3-D work and arises as a result of this and therefore, are not structure directing. There are some weak non-covalent $\pi-\pi$ stacking interactions [38] between the parallel aromatic rings of the adjacent chains, as shown in Fig. 8 and 9. The interplanar distance of the aromatic rings (Fig. 8) is 3.965() $\AA$, which is appreciably shorter than the normal 
$\pi-\pi$ stacking [39]. Consequently, the $\pi-\pi$ stacking interactions also allow the 1D zig-zag structure to form a 3D network (Fig. 9). Thus, lone pair activity and $\pi-\pi$ stacking may control the coordination sphere of lead(II) ions in this complex. The obvious question then is whether the lone pair activity has stretched coordinate bonds, which would result in ligand stacking, or whether it is the stacking interaction, which results in donor atoms forming a gap in the coordination sphere. However, there could be a cooperative effect of the $\pi-\pi$ interactions and the presence of the lone pair in producing closer packing of the structure.

Figure 8

Figure 9\}

$\mathrm{PbO}$ nano powders have been prepared by thermolysis of $\mathbf{1}$ at $180{ }^{\circ} \mathrm{C}$ with oleic acid as the surfactant. The powder XRD patterns (Fig. 10) match with the standard pattern of orthorhombic PbO with $a=5.8931 \AA$ and $Z=4$ (JCPDS card file No. 77-1971), which confirms the formation of $\mathrm{PbO}$ powder. The significant broadening of the peaks of the nanostructure indicates that the particles have nanometer dimensions as confirmed by the value calculated using the Scherrer formula, i.e. $30 \mathrm{~nm}$ (comparable with TEM and SEM). The morphology and size of the PbO samples were further investigated using SEM and TEM. The bulk powder of $\mathbf{1}$ produces regularly shaped $\mathrm{PbO}$ nanoparticles with diameter of about $30 \mathrm{~nm}$ (Figs 11 and 12), which is compatible with similar reported processes [40-42].

Figure 10

Figure 11

Figure 12 
Thermo-gravimetric (TG) and differential thermal analyses (DTA) were performed on $\mathbf{1}$ from 25 to $800{ }^{\circ} \mathrm{C}$ under a nitrogen atmosphere (Fig. 13). The complex dehydrates between 62 and $149{ }^{\circ} \mathrm{C}$ with a mass loss of $3.6 \%$ (calcd. $3.7 \%$ ), ascribed to the loss of water, and the anhydrous compound melts at $174{ }^{\circ} \mathrm{C}$. Then, the simultaneous removal of both $\mathrm{N}_{3}$ and the 2-pinh anion is observed exothermically in the range of 200 to $494{ }^{\circ} \mathrm{C}$, leading to the formation of $\mathrm{PbO}$. The corresponding mass loss of $52.5 \%$ is consistent with the calculated value of $54.2 \%$. Melting of $\mathrm{PbO}$ occurs at ca. $850^{\circ} \mathrm{C}$.

\section{Figure 13}

\section{NBO Analysis}

The NBO analysis shows the total natural charge of lead atoms (1.39 for Pb1). The positively charged $\mathrm{Pb}(1)$ atom is closely surrounded by four electronegative atoms: $\mathrm{O} 2$, $\mathrm{N} 3$, N4, and N7, which have natural charges of $-0.830,-0.587,-0.410$, and -0.729 , respectively. The electronic properties of the $\mathrm{Pb}(1)$ atom are well characterized by second-order perturbation theory analysis of the Fock matrix and demonstrate that antibonding lone pairs of lead are strongly electron donating due to the $\mathrm{N}_{3}$ group. The NBO analysis indicated 79 stabilization interactions over a threshold of $0.50 \mathrm{kcal} / \mathrm{mol}$ between filled Lewis-type NBOs of the azide group (donor) and formally empty nonLewis NBO of the $\mathrm{Pb} 1$ atom (acceptor). The total second-order stabilization energy $\mathrm{E}^{(2)}$ is $115.7 \mathrm{kcal} / \mathrm{mol}$, which is calculated as the sum of $\mathrm{E}^{(2)}$ for alpha and beta spin orbitals.

Critical roles are played in stabilizing the chemical structure by the three interactions listed in table 2 between the donor lone pair orbital on the nitrogen atom LP(N7) and the acceptor lone pair antibonding orbital on the lead atom $(\mathrm{LP}(\mathrm{N} 7) \rightarrow \mathrm{LP} *(\mathrm{~Pb} 1))$. N7-Pb1 interaction is also responsible for breaking the $\mathrm{D}_{2 \mathrm{~h}}$ symmetry of the linear azide group and the difference between the N7-N8 and N8-N9 distances. The presence of an electronpositive lead atom closer to the nitrogen $\mathrm{N} 7$ results in inequality of the natural charge of peripheral nitrogen atoms (-0.73 for N7 and -0.19 for N9). It also results in asymmetric electronic structure of the azide group (for example, asymmetric NBO bond arrangement: only one $\sigma_{\mathrm{N} 7-\mathrm{N} 8}$ bond versus one $\sigma_{\mathrm{N} 8-\mathrm{N} 9}$ plus two $\pi_{\mathrm{N} 8-\mathrm{N} 9}$ bonding orbitals). 
Interactions between lone pairs of $\mathrm{N} 3, \mathrm{~N} 4$, and $\mathrm{O} 2$ atoms with respective antibonding lone pairs of $\mathrm{Pb} 1$ give the strongest stabilization effect (see table 3). Therefore, lead is finely fixed on its position. Other stabilizing interactions have much less energetic importance, such as $\quad \sigma_{\mathrm{O} 2-\mathrm{C} 21} \rightarrow \mathrm{LP} 4 *(\mathrm{~Pb} 1), \quad \mathrm{LP} 1(\mathrm{~N} 32) \rightarrow \mathrm{LP} 4 *(\mathrm{~Pb} 1), \quad$ and $\quad \mathrm{BD}_{\mathrm{N} 5-}$ $\mathrm{C} 19 \rightarrow \mathrm{LP} 3 *(\mathrm{~Pb} 1)$. The NBO orbitals involved in donor-acceptor interaction with $\mathrm{Pb} 1$ are shown as rendered spheres in Fig. 14. It should be noted that antibonding lone pairs of $\mathrm{Pb} 1$ have positive but very low energy (only 0.0004 to 0.04 a.u.). Therefore, they have relatively high occupancy (e.g., $0.3 e$ for $\mathrm{LP} 2 * \mathrm{~Pb} 1$ ) and play an important role in the delocalization effect.

\section{Table 2}

Figure 14

The total steric exchange energy [43] arises almost entirely from the organic unit. About $2 \%$ of the total steric energy is delivered by LP1(Pb1) NLMO (natural localized molecular orbital; table 3).

Table 3

\section{Conclusions}

A novel lead(II) coordination polymer containing a terminal azide anion, $[\mathrm{Pb}(\mu-2-$ pinh $\left.)\left(\mathrm{N}_{3}\right) \mathrm{OH}_{2}\right]_{\mathrm{n}}$ (1), was synthesized by a straightforward sonochemical method. This coordination polymer can be used for the preparation of $\mathrm{PbO}$ nanoparticles. The crystal structure shows the complex to form a one-dimensional zigzag polymer. The arrangement of the ligands suggests a gap in the coordination geometry around the metal ions, which is likely occupied by a stereochemically active lone pair of electrons on lead(II). Lone pair activity and $\pi-\pi$ stacking may control the coordination sphere of lead(II) ions in this complex. 
A new theoretical method was used to examine the electronic structure and determine the electronic properties of lead atoms. The electronic properties of the $\mathrm{Pb}(1)$ atom were well characterized by second-order perturbation theory analysis of the Fock matrix, which demonstrated that antibonding lead lone pairs are strongly electron-donating due to the $\mathrm{N}_{3}$ group. Three interactions between the donor lone pair orbital on the nitrogen atom $(\mathrm{LP}(\mathrm{N} 7))$ and the acceptor lone pair antibonding orbital on the lead atom (LP(N7) $\rightarrow$ $\mathrm{LP} *(\mathrm{~Pb} 1))$ play a critical role in stabilizing the chemical structure. Also, interactions between lone pairs of $\mathrm{N} 3, \mathrm{~N} 4$, and $\mathrm{O} 2$ atoms with respective antibonding lone pairs of $\mathrm{Pb} 1$ give the strongest stabilization effect, which result in lead being finely fixed on its position. Antibonding lone pairs of $\mathrm{Pb} 1$ have positive but very low energy (only 0.0004 to 0.04 a.u.). Therefore, they have relatively high occupancy (e.g., $0.3 e$ for $\mathrm{LP} 2 * \mathrm{~Pb} 1)$ and play an important role in the delocalization effect.

\section{Experimental section}

\section{Materials and physical measurements}

2-Pyridinecarbaldehyde isonicotinoylhydrazone (H-2-pinh) was synthesized according to a literature method [44]. All other chemicals were obtained from commercial sources and used without further purification. Ultrasound was applied using a multi-wave ultrasonic generator (Sonicator_3000; Misonix Inc., Farmingdale, NY, USA), which was equipped with a converter/transducer and titanium oscillator (horn; $12.5 \mathrm{~mm}$ diameter). The generator was operated at room temperature for $1 \mathrm{~h}$ at $20 \mathrm{kHz}$ with a maximum power output of $600 \mathrm{~W}$. Infrared spectra were recorded using $\mathrm{KBr}$ pellets with a Perkin-Elmer 883-IR spectrophotometer and a Nicolet 520 FTIR spectrophotometer. Elemental analyses $(\mathrm{C}, \mathrm{H}, \mathrm{N})$ were performed on a Perkin-Elmer 2400 II elemental analyser. X-ray powder diffraction (XRD) measurements were performed with monochromatized $\mathrm{CuK}_{\alpha}$ radiation using an X'pert diffractometer manufactured by the Panalytical company. Simulated XRD powder patterns based on single-crystal data were prepared using the Mercury program [45]. 
The crystallite sizes of selected samples were estimated using the Scherrer formula. The samples were characterized using a scanning electron microscope and gold coating. Melting points were measured on an Electrothermal 9100 apparatus and are uncorrected. Thermal analysis curves (TG and DTA) were obtained using a Seiko Exstar TG/DTA 6200 thermal analyser in a nitrogen flow with a heating rate of $10 \mathrm{~K} \mathrm{~min}^{-1}$. The sample size was 5-10 mg, and platinum crucibles were used.

\section{Preparation of $\left[\mathrm{Pb}(\mu-2-p i n h)\left(\mathrm{N}_{3}\right) \mathrm{OH}_{2}\right]_{n}$}

To prepare the nano-structure of $\left[\mathrm{Pb}(\mu-2-\text { pinh }) \mathrm{N}_{3} \quad \mathrm{H}_{2} \mathrm{O}\right]_{\mathrm{n}}$ (1), a high-density ultrasonic probe was placed in $15 \mathrm{~mL}$ of a $0.1 \mathrm{M}$ solution of $\mathrm{Pb}\left(\mathrm{CH}_{3} \mathrm{COO}\right)_{2}$ in $\mathrm{H}_{2} \mathrm{O} / \mathrm{MeOH}$ and operated at $20 \mathrm{kHz}$ with a maximum power output of $600 \mathrm{~W}$. To this solution, $15 \mathrm{~mL}$ of $0.1 \mathrm{M} \mathrm{H}$-2-pinh ligand solution which solvent? and $15 \mathrm{~mL}$ of $0.1 \mathrm{M}$ sodium azide which solvent? were added dropwise. The obtained precipitates were filtered off, washed with water, and dried in air.

Product 1: m.p. $=173{ }^{\circ} \mathrm{C}$. Analysis: Found; C: 30.00, H: 2.20, N: $20.00 \%$. calcd. for $\mathrm{C}_{12} \mathrm{H}_{11} \mathrm{~N}_{7} \mathrm{O}_{2} \mathrm{~Pb}: \mathrm{C}: 29.27, \mathrm{H}: 2.25, \mathrm{~N}: 19.91 \%$.

IR (selected bands; in $\mathrm{cm}^{-1}$ ): 700s, 761m, 855m, 1024m, 1151m, 1350s, 1463m, 1576m, $1603 m, 2021 v s, 2923 m, 3423 b r \mathrm{~cm}^{-1}$ [37].

To isolate single crystals of $1, \mathrm{H}-2$-pinh $(0.23 \mathrm{~g}, 1 \mathrm{mmol})$ was placed in one arm of a branched tube, while $\mathrm{Pb}\left(\mathrm{CH}_{3} \mathrm{COOH}\right)_{2}(0.32 \mathrm{~g}, 1 \mathrm{mmol})$ and sodium azide $(0.07 \mathrm{~g}, 1$ mmol) were placed in the other. Methanol was then carefully added to fill both arms, and the tube was sealed. The ligand-containing arm was immersed in a bath at $60{ }^{\circ} \mathrm{C}$, while the other arm was left at ambient temperature. After 2 weeks, crystals (m.p. $175{ }^{\circ} \mathrm{C}$ ) suitable for X-ray structure determination were deposited in the arm kept at ambient temperature. They were then filtered off, washed with acetone and ether, and air dried (yield: $73 \%$ ). Analysis: Found; C: $29.20, \mathrm{H}: 2.20, \mathrm{~N}: 19.80 \%$. calcd. for $\mathrm{C}_{12} \mathrm{H}_{11} \mathrm{~N}_{7} \mathrm{O}_{2} \mathrm{~Pb}$ : C: $29.27, \mathrm{H}: 2.25, \mathrm{~N}: 19.91 \%)$.

IR (selected bands; in $\mathrm{cm}^{-1}$ ): 699s, 761m, 854m, 1023m, 1149m,13509s, 1461m, 1565m, $1601 \mathrm{~m}, 2023 \mathrm{vs}, 2923 \mathrm{~m}, 3419 \mathrm{br} \mathrm{cm}^{-1}$ [37]. 


\section{Crystallography}

Intensity data were collected at 298(2) $\mathrm{K}$ with a Bruker SMART APEX diffractometer using graphite monochromatic Mo $\mathrm{K} \alpha$ radiation $(\lambda=0.71073 \AA)$. An absorption correction (SADABS [46]) was applied. The structure was solved by direct methods using SHELXS-97 [47] and refined by full-matrix least squares using SHELX2014/7 [48] employing standard procedures. The molecular structure was drawn at the $50 \%$ displacement level with ORTEP for Windows [49] and other crystallographic diagrams were drawn with DIAMOND [50]. Crystal data and refinement details are given in Table 1. The crystallographic data for the structure have been deposited at the Cambridge Crystallographic Data Centre as supplementary publication CCDCXXXXXX for 1. Copies of the data can be obtained upon request from CCDC, 12 Union Road, Cambridge CB2 1EZ, UK [Fax: +44-1223-336033; E-mail: de-posit@ccdc.cam.ac.uk].

\section{Theoretical methods}

The natural bond orbital (NBO) analysis was performed using the standalone NBO program version 5.0 [50]. NBO version 3.1 as implemented in the Gaussian 98, 03, and 09 packages and produces very similar natural bond analysis results compared with the new version of the NBO program. However, NBO 5.0 is much more detailed when describing the electronic structure. For example, it can illustrate the localized NBO/NLMO contributions to the steric exchange energy [51].

\section{Acknowledgments}

Support from the University of Qom is gratefully acknowledged. This work was funded by Grant NRF-2015-002423 of the National Research Foundation of Korea. The theoretical calculations were financed by a statutory activity subsidy from the Polish Ministry of Science and Higher Education for the Faculty of Chemistry of Wroctaw University of Technology. DB acknowledge generous computer time from the Wroctaw Supercomputer and Networking Center.

\section{References}

1. R. Chakrabarty, P.S.Mukherjee, P.J. Stang, Chem.Rev.111 (2011) 6810-6918. 
2. A. Erxleben,Coord. Chem. Rev.246 (2003) 203-228.

3. C.L. Cahill, D.T. de Lill, M. Frisch, CrystEngComm 9 (2007) 15-26.

4. A. Morsali,L.-G.Zhu, Helv.Chim.Acta 89 (2006)81-93.

5. S.R. Batten,S.M.Neville,D.R.Turner, The Royal Society of Chemistry 89 (2009).

6. C. Janiak, Dalton Trans. (2003)2781-2804.

7. H. Li,J.Zhai,X.Sun, RSC Adv.1(2011)725-730.

8. K. Kavallieratos, J. M. Rosenberg, J. C. Bryan, Inorg. Chem., 44 (2005) 2573-2575.

9. Lindoy, L. F. Pure Appl. Chem. 69 (1997) 2179.

10. Hancock, R. D.; Martell, A. E. Chem. ReV. 89 (1989) 1875.

11. L. M Engelhardt, B. M. Furphy, J. M. Harrowfield, J. M. Patrick, A. H. White, Inorg. Chem. 28 (1989) 1410.

12. L. Shimonni-Livny, J. P. Glusker, C. W.Bock, Inorg. Chem. 37 (1998) 1853.

13. J. S. Casas, J. Sordo, LEAD, Chemistry, Analytical Aspects, Environmental Impact and Health Effects, First edition 2006, Elsevier.

14. A. Walsh and G.W. Watson, J. Solid State Chem., 178 (2005) 1422.

15. N. Soltanzadeh, A. Morsali, Ultrason. Sonochem. 17 (2010)139-144.

16. H. Sadeghzadeh, A. Morsali, CrystEngComm 12 (2010)370-372.

17. V. Safarifard, A. Morsali, Coord. Chem. Rev. 292 (2015) 1-14.

18. S. M. Soliman, J. Mol. Struct. 1048 (2013) 308-320.

19. S. M. Soliman, T.S. Kassem, A.M.A. Badr, M.A. Abu Youssef, R. Assem, J. Mol. Struct. 1074 (2014) 168-179.

20. M. Nora, M. Fatiha, N. Leila, H. Sakina, K. DjamelEddin, J. Mol. Liq. 211 (2015) $40-47$.

21. Z.K. Eddine, M. Fatiha, Z. Amal, N. Leila, M. Rachid, C. R. Chimie 18 (2015) $193-$ 198.

22.Shaabani, B., Mirtamizdoust, B., Viterbo, D., Croce, G., Hammud, H., Hojati-Lalemi, P., Khandar, A., Z. Anorg. Allg. Chem., 637 (2011) 713-719.

23. B. Mirtamizdoust, B. Shaabani, S.W. Joo, D. Viterbo, G. Croce, Y. Hanifehpour, J. Inorg. Organomet. Polym., 22, 1397-1403 (2012).

24. Shaabani, B., Mirtamizdoust, B., Shadman, M., Fun, H. K., Z. Anorg. Allg. Chem., 635 (2009) 2642-2647. 
25. Mirtamizdoust, B., Shaabani, B., Khandar, A., Fun, H. K., Huang, S., Shadman, M., Hojati-Talemi, P., Z. Anorg. Allg. Chem., 638 (2012) 844-850.

26. Hanifehpour, Y., Mirtamizdoust, B., Joo, S. W., J. Inorg. Organomet. Polym., 22 (2012) 916-922.

27. Hanifehpour, Y., Mirtamizdoust, B., Farzam, A. R., Joo, S. W., J. Inorg. Organomet. Polym., 22(2012) 957-962.

28. Mirtamizdoust, B., Ali-Asgari, S., Joo, S. W., Maskani, E., Hanifehpour, Y., Oh, T. H., J. Inorg. Organomet. Polym., 23 (2013) 751-757.

29. Hanifehpour, Y., Morsali, A., Mirtamizdoust, B., Joo, S. W., J. Mol. Struct., 1079 (2015) 67-73.

30. Mirtamizdoust, B., Shalamzari, M. S., Behrouzi, S., Florencio, M. H., Fun, H. K., J. Inorg. Organomet. Polym., 22 (2012) 1358-1364.

31. Hanifehpour, Y., Mirtamizdoust, B., Morsali, A., Joo, S. W., Ultrason. Sonochem., 23 (2015) 275-281.

32. Hanifehpour, Y., Mirtamizdoust, B., Morsali, A., Joo, S. W., Ultrason. Sonochem., 23 (2015) 275-281.

33. Hanifehpour, Y., Morsali, A., Mirtamizdoust, B., Joo, S. W., J. Mol. Struct., 1079 (2015) 67-73.

34. Y. Hanifehpour, V. Safarifard, A. Morsali, B. Mirtamizdoust, S.W. Joo, Ultrason. Sonochem. 23 (2015) 282-288.

35. Y. Hanifehpour, B. Mirtamizdoust, B. Khomami, S.W. Joo, Z. Anorg. Allg. Chem. 641 (2015) 2466-2472

36. J.M. Harrowfield, H. Miyamae, B.W. Skelton, A.A. Soudi, A.H. White, Aust. J. Chem. 49 (1996) 1165, and references therein.

37. L. K. Nakamoto. Infrared and Raman Spectra of Inorganic and Coordination Compounds (Wiley, New York, 1997), 5th Edn., Part B, pp. 124-126.

38. N. N. Greenwood, A. Earnshaw, Chemistry of the Elements, Pergamon Press, Oxford, 1986, 235-254.

39. C.A. Hunter, J.K.M. Sanders, J. Am. Chem. Soc. 1990, 112, 5525-5534.

40. K. Akhbari, A. Morsali, CrystEngComm. 13, 2047 (2011).

41. L. Hashemi, A. Morsali, P. Retailleau, Inorganica Chimica Acta 367, 207 (2011). 
42.H. Sadeghzadeh, A. Morsali, Ultrasonics Sonochemistry, 18, 80 (2011).

43. J. K. Badenhoop and F. Weinhold, J. Chem. Phys. 107, 5406-5421, 5422-5432 (1997).

44. C.M. Armstrong, P.V. Bernhardt, P. Chin, D.R. Richardson, Eur. J. Inorg. Chem. (2003) 1145.

45. Mercury 2.4, Copyright Cambridge Crystallographic Data Centre, 12 Union Road, Cambridge, CB2 1EZ, UK, 2001-2010.

46. G.M. Sheldrick, SADABS, University of Göttingen, Germany, 1996.

47. G.M. Sheldrick. Acta Crystallogr. A 64 (2008) 112.

48. G.M. Sheldrick. Acta Crystallogr. C 71 (2015) 3.

49. L. J. Farrugia, J. Appl. Crystallogr. 45 (2012) 849.

50. K. Brandenburg, DIAMOND. Crystal Impact GbR, Bonn, Germany, 2006.

50. NBO 5.0., E. D. Glendening, J. K. Badenhoop, A. E. Reed, J. E. Carpenter, J. A.

Bohmann, C. M. Morales, and F. Weinhold (Theoretical Chemistry Institute, University of Wisconsin, Madison, WI, 2001); http://www.chem.wisc.edu/ nbo5.

51. J. K. Badenhoop and F. Weinhold, Int. J. Quantum Chem. 72 (1999) 269-280.

52. A. Angelova, B. Angelov, R. Mutafchieva, S. Lesieur, J. Inorg. Organomet. Polym., 25 (2015) 214-232.

53. N.N. Gubanova, Y. Ye. Baranchikov, G.P. Kopitsa, L. Almásy, B. Angelov, A.D.

Yapryntsev, L. Rosta, V.K. Ivanov, Ultrason. Sonochem. 24 (2015) 230-237.

54. B. Angelov, A. Angelova, M. Drechsler, V.M. Garamus, R. Mutafchieva, S. Lesieur, Soft Matter, 11 (2015) 3686-3692. 
Table 1. Crystal data and refinement details for $\left[\mathrm{Pb}(\mu-2-\text { pinh })\left(\mathrm{N}_{3}\right) \mathrm{OH}_{2}\right]_{\mathrm{n}}(\mathbf{1})$

\begin{tabular}{|c|c|}
\hline Empirical formula & $\mathrm{C}_{12} \mathrm{H}_{11} \mathrm{~N}_{7} \mathrm{O}_{2} \mathrm{~Pb}$ \\
\hline Formula weight & 492.47 \\
\hline Crystal system & orthorhombic \\
\hline Space group & Pbcn \\
\hline $\mathrm{a} / \AA$ & $12.6325(10)$ \\
\hline $\mathrm{b} / \AA$ & $16.5639(13)$ \\
\hline$c / \AA$ & $13.7687(11)$ \\
\hline Volume $/ \AA^{3}$ & $2881.0(4)$ \\
\hline $\mathrm{Z}$ & 8 \\
\hline$\rho_{\text {cald }} / \mathrm{mg} \mathrm{mm}^{-3}$ & 2.271 \\
\hline$\mu / \mathrm{mm}^{-1}$ & 11.731 \\
\hline $\mathrm{F}(000)$ & 1840 \\
\hline Crystal size $/ \mathrm{mm}^{3}$ & $0.10 \times 0.20 \times 0.40$ \\
\hline $2 \theta$ range for data collection ${ }^{\circ}$ & 4.0 to 55.0 \\
\hline Reflections collected & 25636 \\
\hline Independent reflections & $3312\left[\mathrm{R}_{\text {int }}=0.067\right]$ \\
\hline Data with $I \geq 2 \sigma(I)$ & 2238 \\
\hline Goodness-of-fit on $\mathrm{F}^{2}$ & 1.01 \\
\hline Final $\mathrm{R}$ indexes [obs. data] & $\mathrm{R}_{1}=0.026, \mathrm{wR}_{2}=0.056$ \\
\hline Final $\mathrm{R}$ indexes [all data] & $\mathrm{R}_{1}=0.059, \mathrm{wR}_{2}=0.070$ \\
\hline \multicolumn{2}{|c|}{ Largest diff. peak/hole / e $\AA^{-3} 1.12 /-1.01$} \\
\hline
\end{tabular}


Table 2. Second-order interaction energy $\left(E^{2}, \mathrm{kcal} / \mathrm{mol}\right)$ between donor $\rightarrow$ acceptor orbitals (the molecular units found in the alpha and beta manifolds are not equivalent).

\begin{tabular}{|c|c|c|}
\hline Donor $\quad \rightarrow$ & Second-order inter: & $\operatorname{gy}\left(E^{2}, \mathrm{kcal} / \mathrm{mol}\right)$ \\
\hline $\begin{array}{l}(\mathrm{LP}=\text { lone pair; } \\
\mathrm{BD}=\text { natural bond orbital) }\end{array}$ & alpha spin orbitals & beta spin orbitals \\
\hline LP1 (N7) $\rightarrow$ LP3*Pb(1) & 17.23 & 17.86 \\
\hline LP2 (N7) $\rightarrow$ LP2* Pb(1) & 17.90 & 16.97 \\
\hline LP1 (N7) $\rightarrow$ LP2* Pb(1) & 11.66 & 11.96 \\
\hline $\mathrm{LP} 2(\mathrm{O} 2) \rightarrow \mathrm{LP} 4 * \mathrm{~Pb}(1)$ & 13.46 & 13.29 \\
\hline $\mathrm{LP} 1(\mathrm{~N} 4) \rightarrow \mathrm{LP} 2 * \mathrm{~Pb}(1)$ & 17.77 & 18.08 \\
\hline $\mathrm{LP} 1(\mathrm{~N} 3) \rightarrow \mathrm{LP} 4 * \mathrm{~Pb}(1)$ & 7.79 & 7.74 \\
\hline LP1 (N6) $\rightarrow$ LP2*Pb(31) & 23.00 & - \\
\hline LP1 (N6) $\rightarrow$ LP3*Pb(31) & - & 24.47 \\
\hline $\mathrm{BD}^{*}{ }_{\mathrm{N} 4-\mathrm{Pb} 31} \rightarrow \mathrm{BD}_{\mathrm{N} 4-\mathrm{Pb} 31}$ & - & 34.54 \\
\hline $\mathrm{BD}^{*}{ }_{\mathrm{N} 4-\mathrm{Pb} 31} \rightarrow \mathrm{BD}_{\mathrm{N} 5-\mathrm{C} 19}$ & - & 254.79 \\
\hline
\end{tabular}


Table 3. Steric exchange energy calculated by units.

\begin{tabular}{|c|c|c|}
\hline \multirow[b]{2}{*}{ Unit } & \multicolumn{2}{|c|}{ Steric exchange energy $\left(E_{\text {exchange }}^{\text {NLMO }}, \mathrm{kcal} / \mathrm{mol}\right)$} \\
\hline & alpha spin orbitals & $\begin{array}{l}\text { beta spin } \\
\text { orbitals }\end{array}$ \\
\hline $\mathrm{Pb} 1$ & 16.07 & 15.95 \\
\hline Organic unit & 713.68 & 745.19 \\
\hline $\mathrm{N}_{3}$ group & 65.60 & 58.71 \\
\hline N32 & 2.30 & 0.43 \\
\hline Total steric exchange energy & 804.22 & 843.27 \\
\hline
\end{tabular}




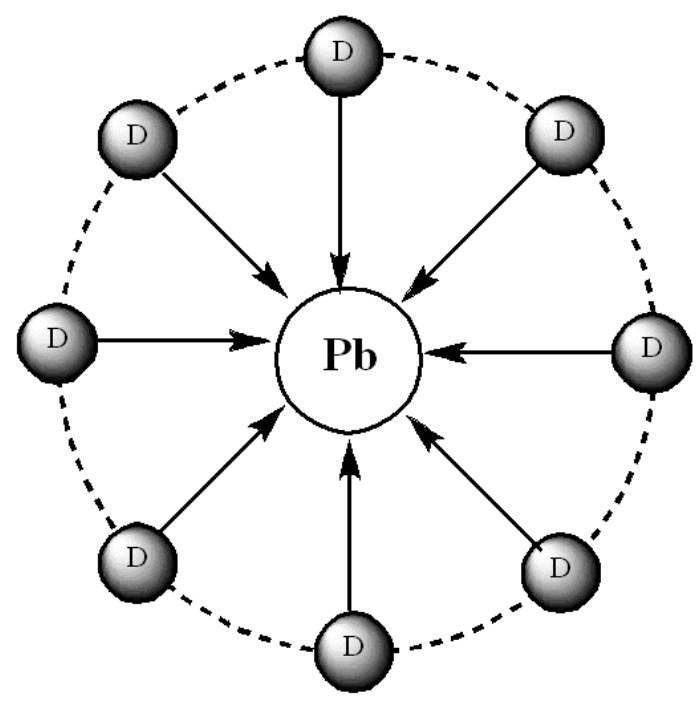

Holodirected

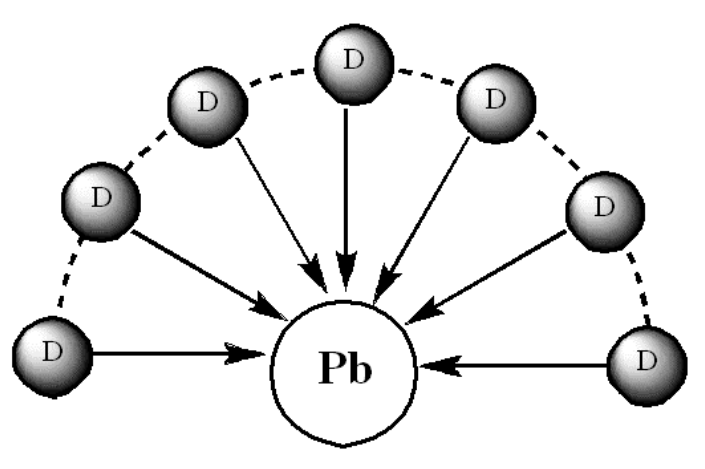

Hemidirected

Scheme 1. Stereochemical influence of the $6 s$ pair on coordination sphere $(\mathrm{D}=$ donor atom of a ligand) 


\begin{tabular}{|c|c|c|}
\hline \multirow{4}{*}{$\mathrm{Pb}\left(\mathrm{CH}_{3} \mathrm{COO}\right)_{2}+\mathrm{NaN}_{3}+\mathrm{H}-2-\mathrm{pinh}$} & Methanol/ $\mathbf{H}_{2} \mathbf{O}$ & thermolysis at $180^{\circ} \mathrm{C}$ \\
\hline & by Ultrasound & \\
\hline & & Pbo nano particle \\
\hline & $\begin{array}{l}\text { Methanol } \\
\text { the heating grac }\end{array}$ & $\overrightarrow{\text { ent }}$ single crystal of compound 1 \\
\hline
\end{tabular}

Scheme 2. Materials produced and synthetic methods. 


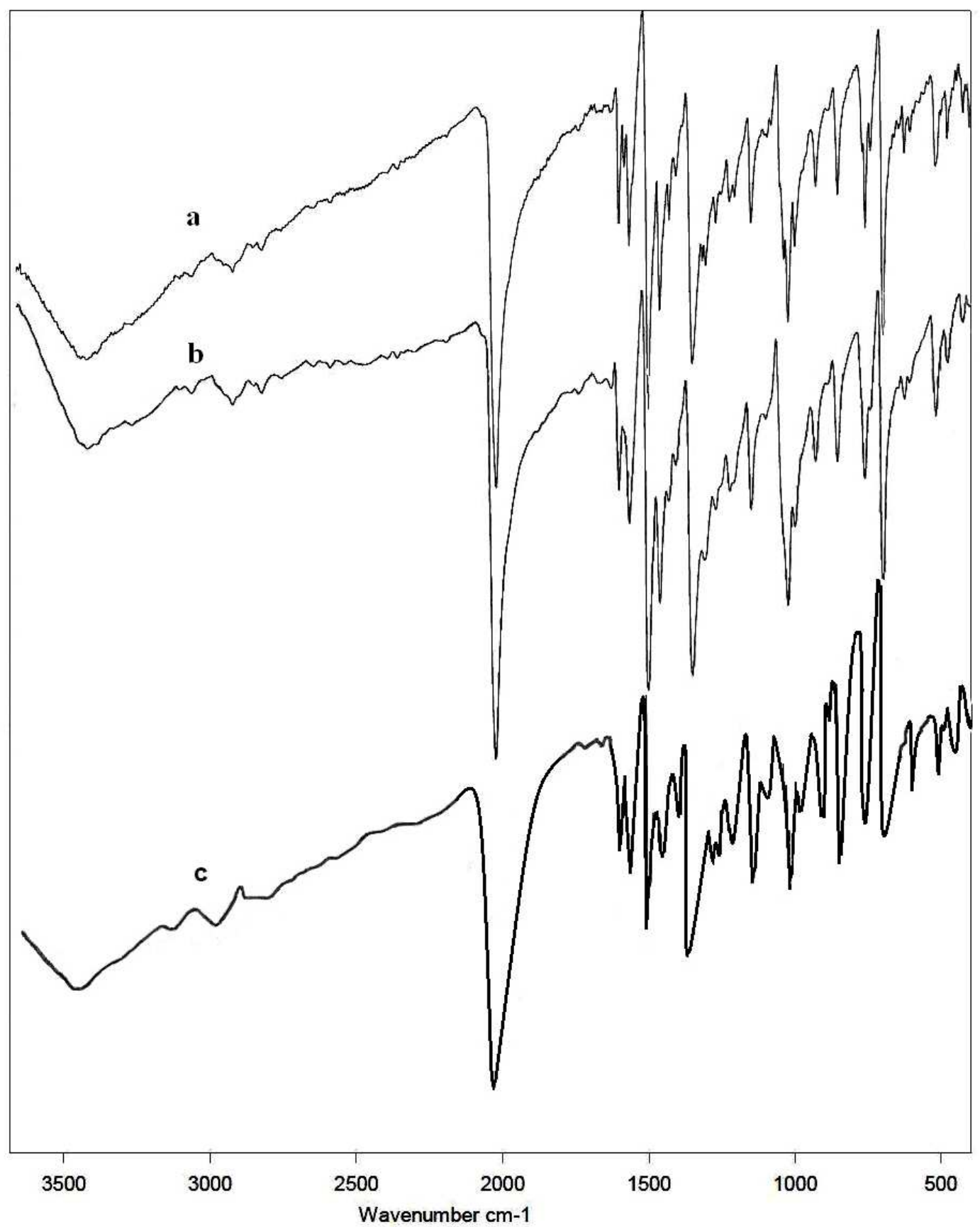

Fig. 1. The FT-IR spectra of $\mathbf{1}$ (a: nanostructures; b: single-crystalline; c: calculated). 


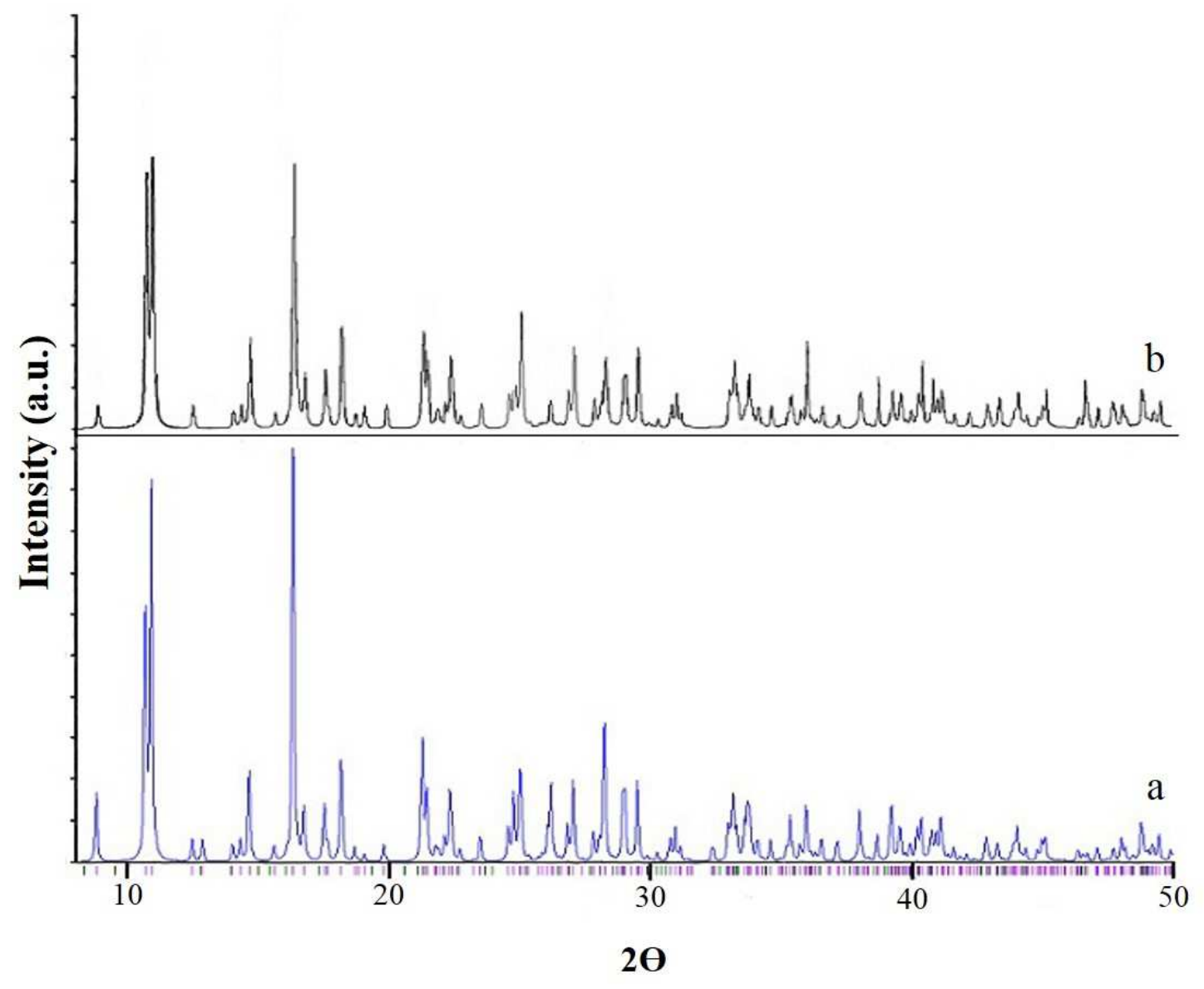

Fig. 2. (a) calculated PXRD from the crystal structure analysis and (b) PXRD from nanostructure of 1 . 


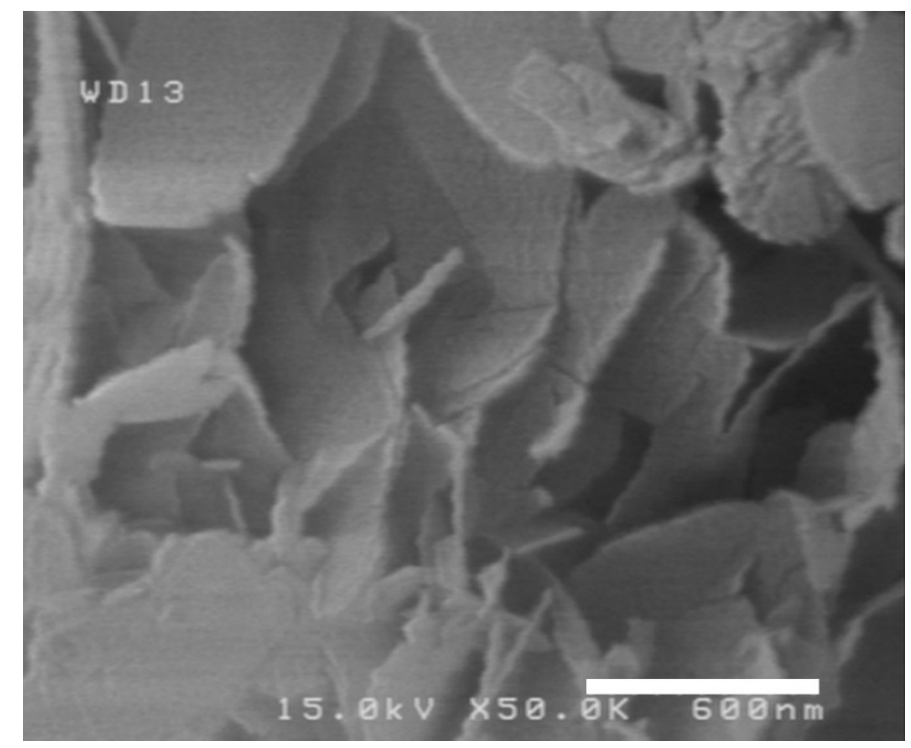

Fig. 3. SEM image of $\left[\mathrm{Pb}(\mu-2-\mathrm{pinh})\left(\mathrm{N}_{3}\right) \mathrm{OH}_{2}\right]_{\mathrm{n}}$ (1) nano-cauliflower. 


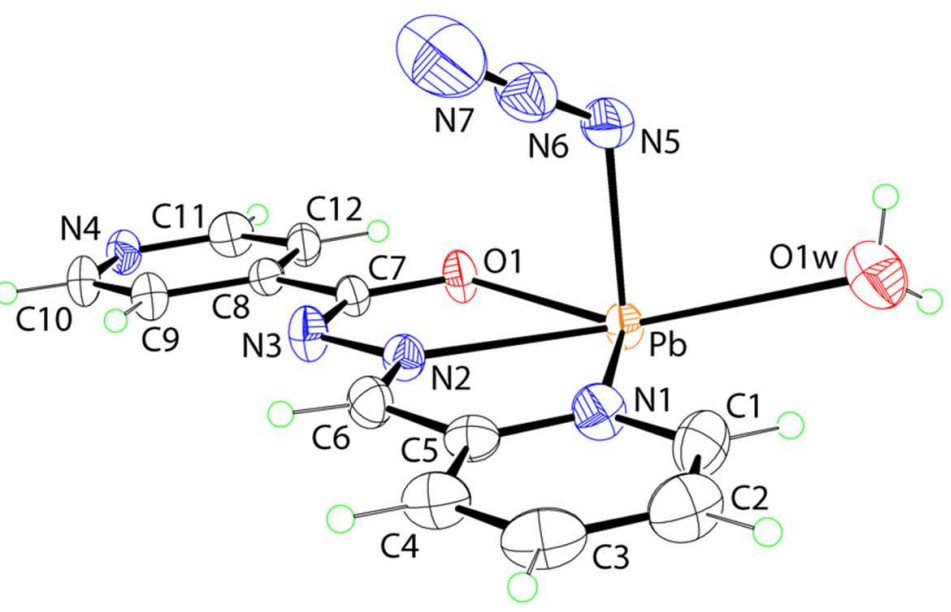

Fig. 4. Molecular structure of the asymmetric unit of $\left[\mathrm{Pb}(\mu-2-\mathrm{pinh})\left(\mathrm{N}_{3}\right) \mathrm{OH}_{2}\right]_{\mathrm{n}}(\mathbf{1})$ showing atom labelling. 


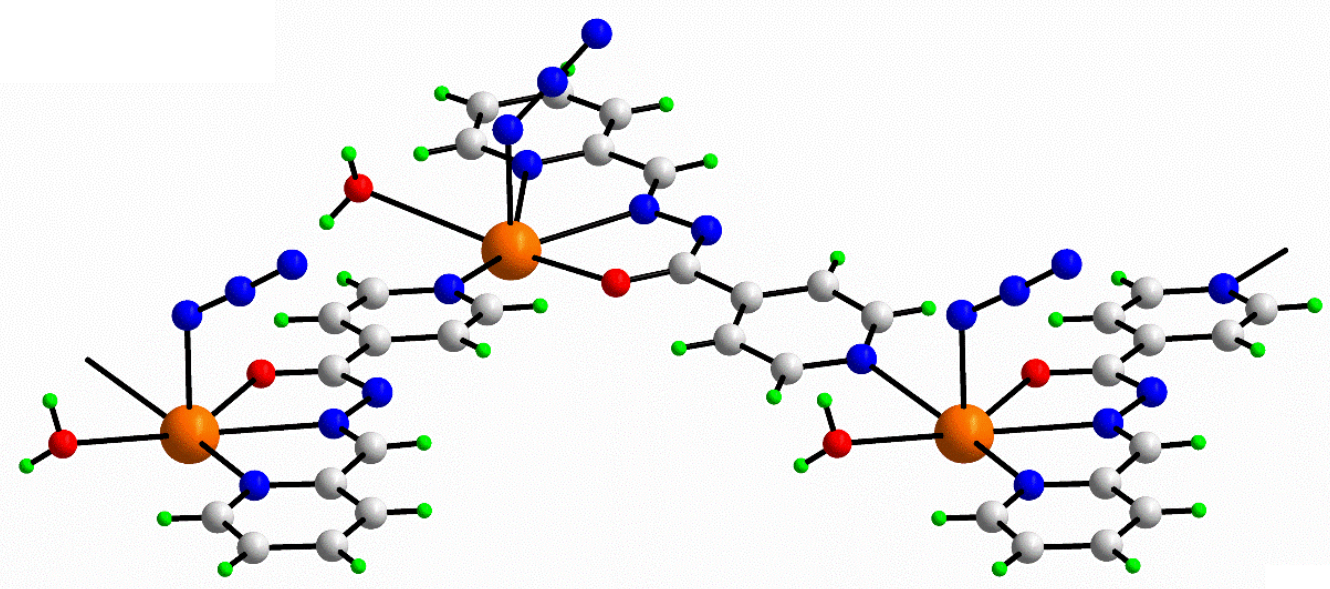

(a)

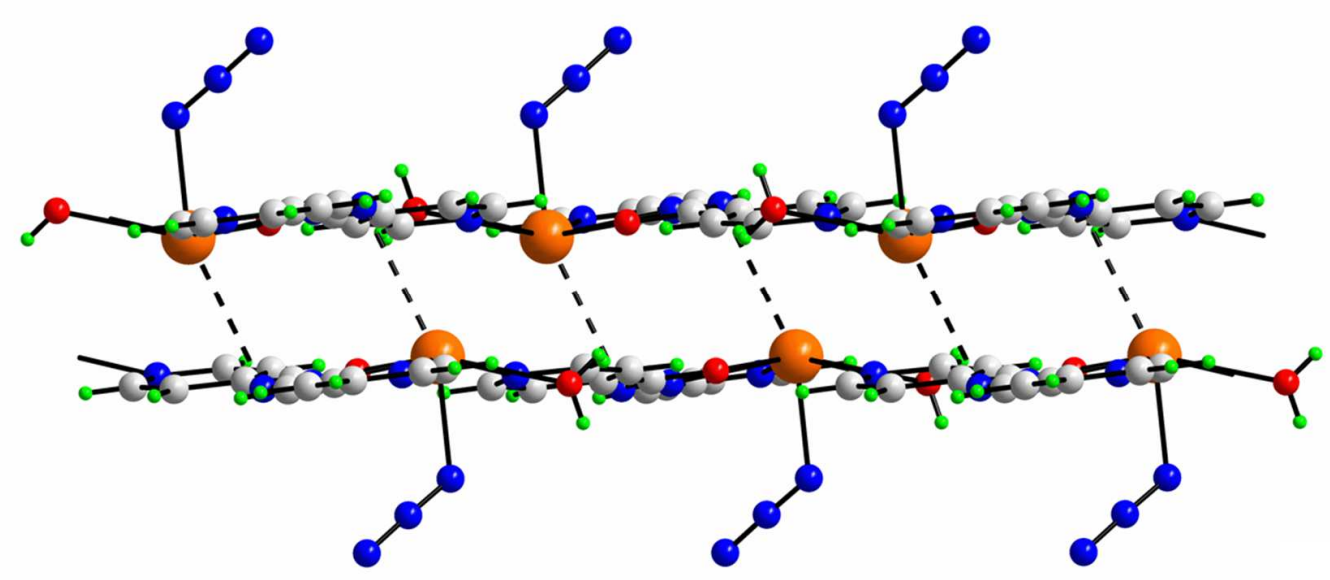

(b)

Fig. 5. (a) Fragment of the coordination polymer showing the 1D zigzag polymeric chain. (b) Association between chains related by 2-fold symmetry via Pb...N3 interactions. 


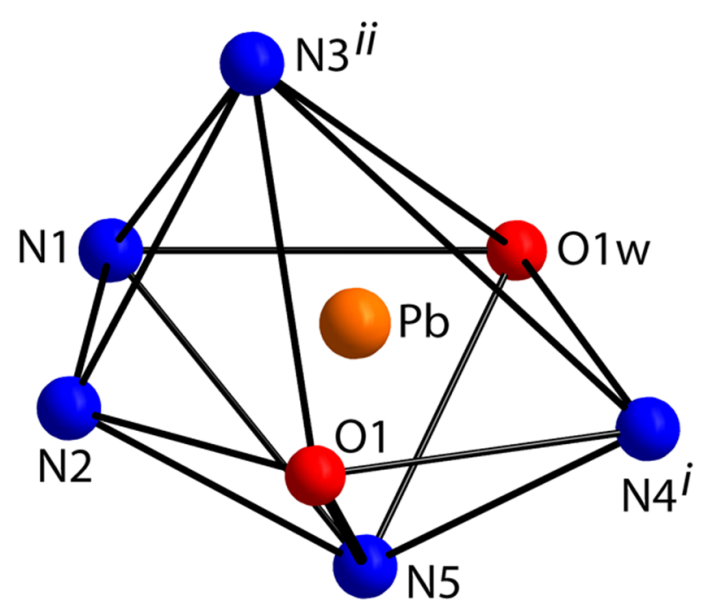

Fig. 6. Immediate environment of lead atom in 1. Bond lengths $[\AA]$ : $\mathrm{Pb}-\mathrm{O} 1=2.404(4)$, $\mathrm{Pb}-\mathrm{O} 1 \mathrm{w}=2.944(5), \mathrm{Pb}-\mathrm{N} 1=2.796(5), \mathrm{Pb}-\mathrm{N} 2=2.546(4), \mathrm{Pb}-\mathrm{N} 5=2.347(6), \mathrm{Pb}-\mathrm{N} 4^{\mathrm{i}}=$ 2.706(5), Pb...N3 $3^{i i}=3.283(5)$. Symmetry operation i: $x, 1-y, 1 / 2+z$ and ii: $1-x, y, 1 / 2-z$. 


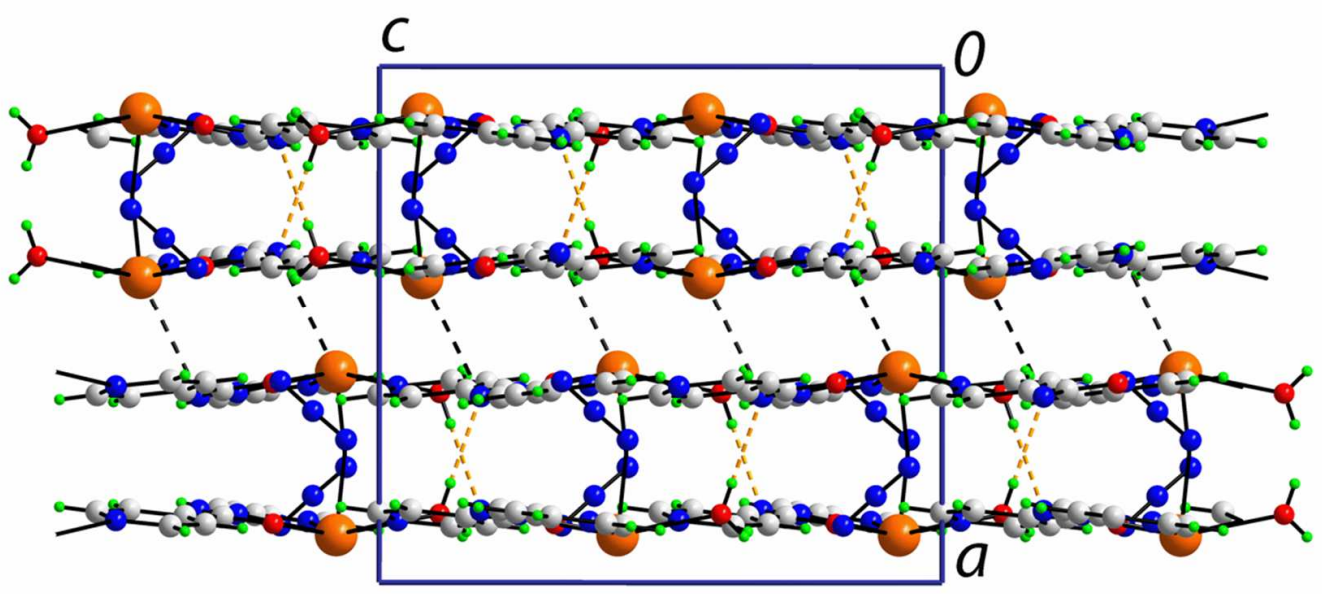

Fig. 7. Unit cell contents of $\mathbf{1}$ shown in projection down the b-axis highlighting the stacking of layers along the a-axis. 


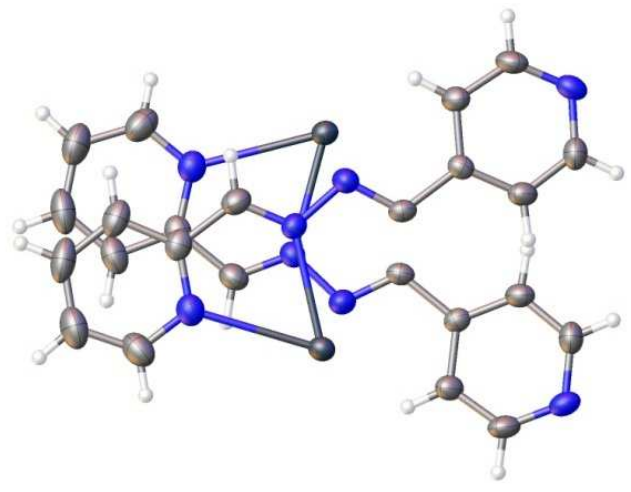

Fig. 8. Projection of the nearest neighbor pairs of $\pi$ - $\pi$ stacks of heteroaromatic bases in $\left[\mathrm{Pb}(\mu-2-\text { pinh }) \mathrm{N}_{3}\left(\mathrm{H}_{2} \mathrm{O}\right)\right]_{\mathrm{n}}$ 


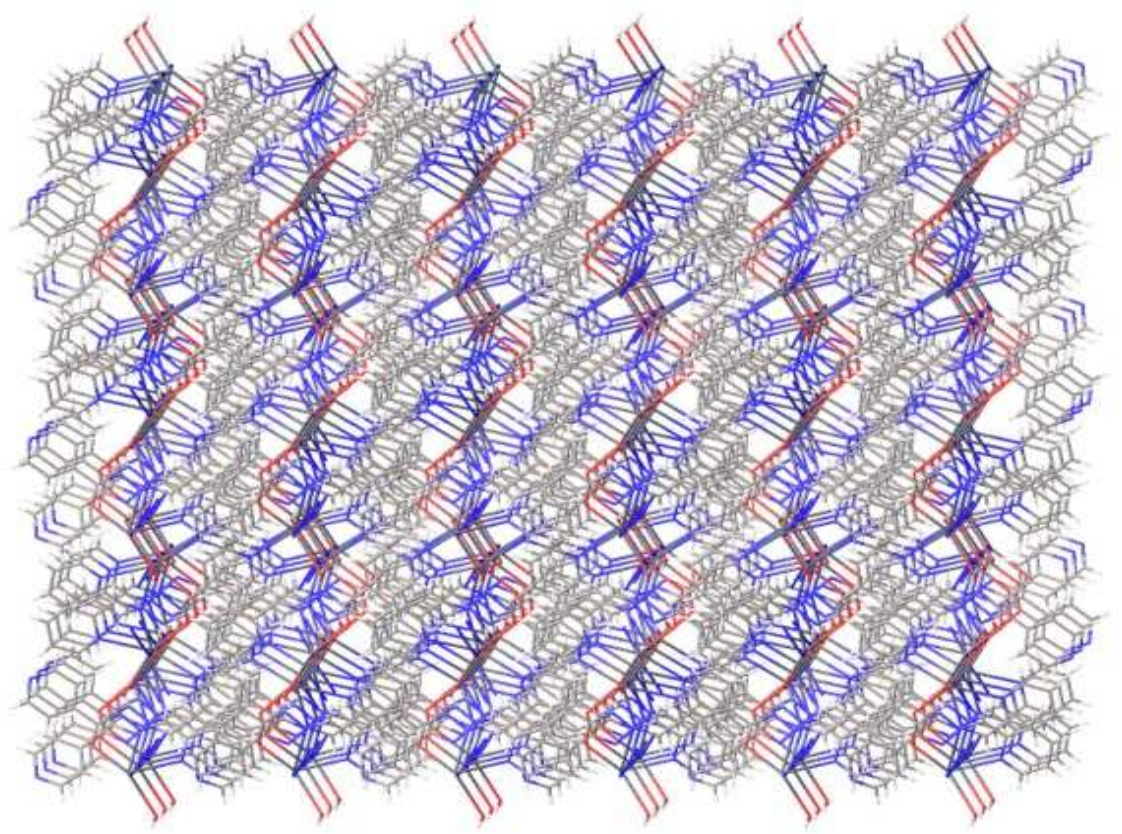

Fig. 9. Packing of $1 \mathrm{D}$ zig-zag chains forming $3 \mathrm{D}$ supramolecular layers via $\pi-\pi$ stacking interactions 


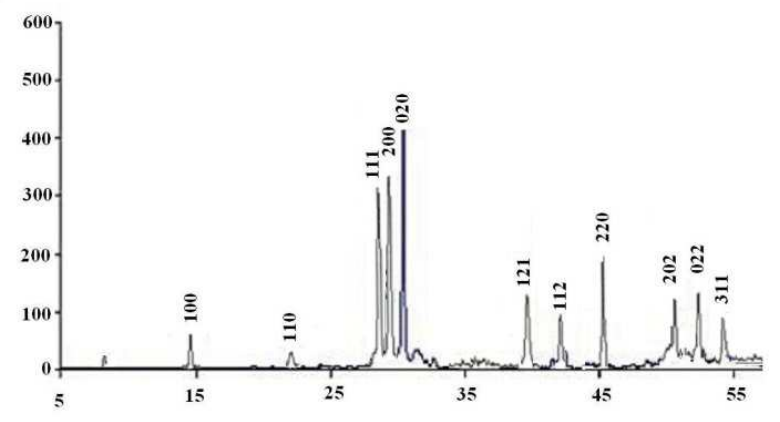

$2 \theta$

Fig. 10. XRD patterns of $\mathrm{PbO}$ after calcination of $\mathbf{1}$. 


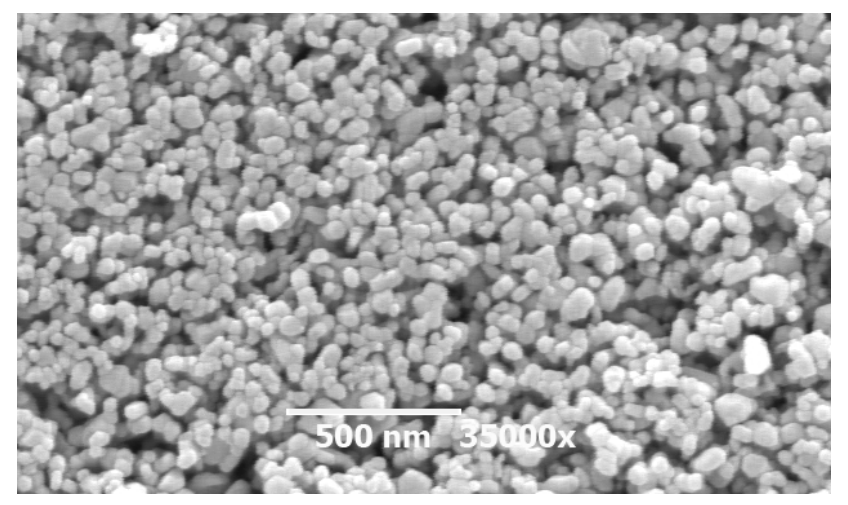

Fig. 11. SEM image of $\mathrm{PbO}$ nano-powder (produced by calcination of nanocauliflower). 


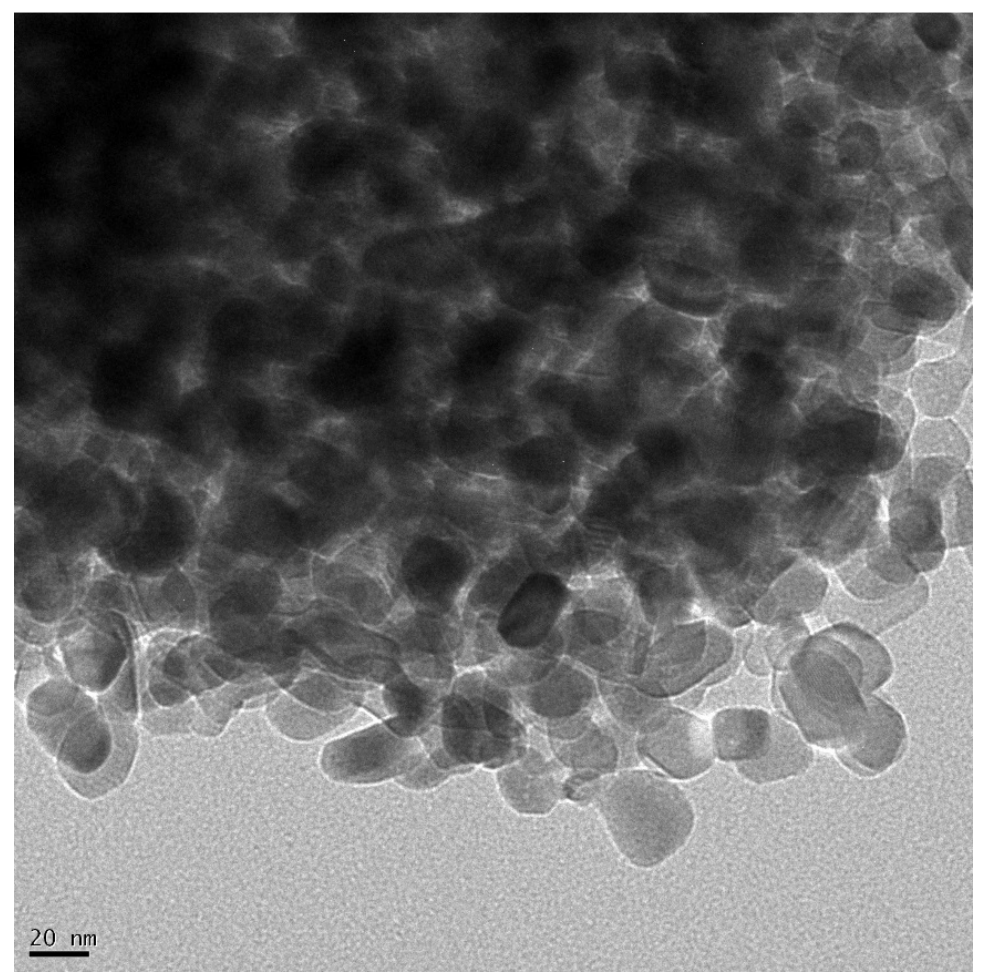

Fig. 12. TEM image of $\mathrm{PbO}$ nano-powder (produced by calcination of nanocauliflower). 


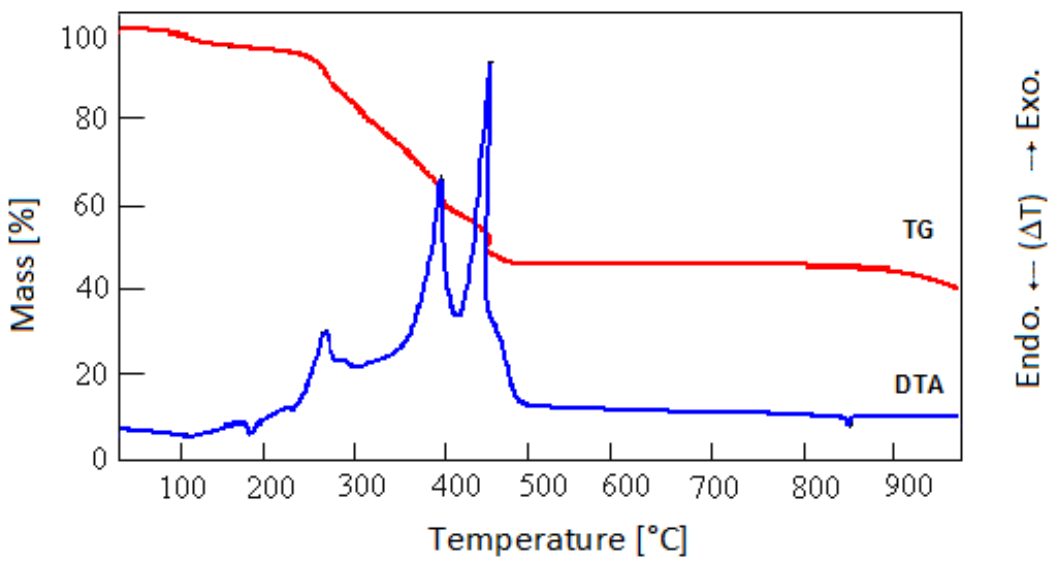

Fig. 13 Thermal analysis of complex (1): TG and DTA curves. 


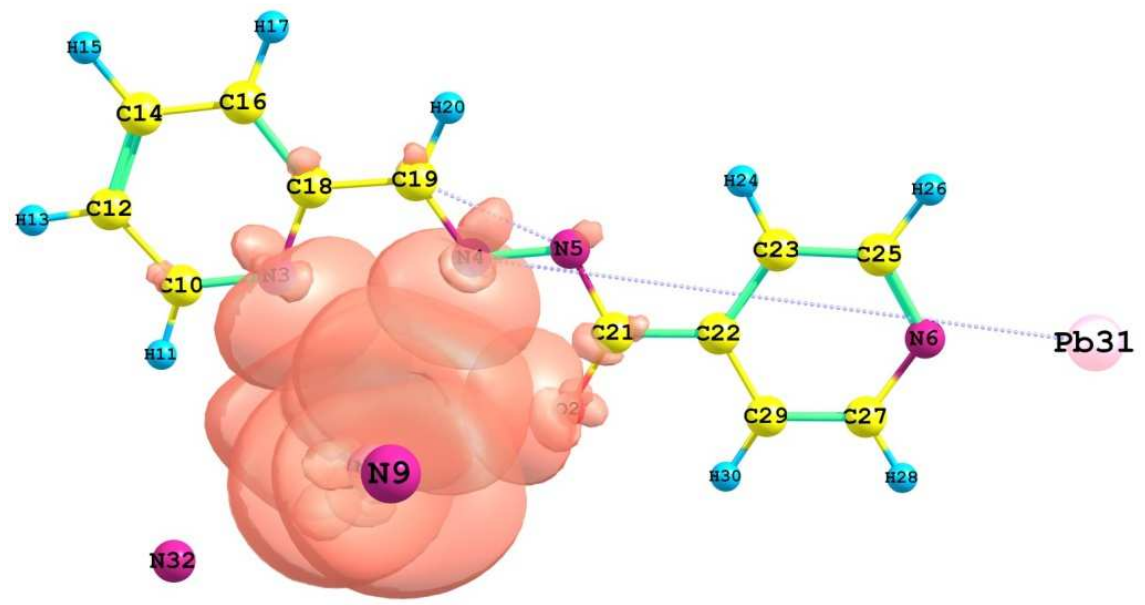

Fig. 14. Donor-acceptor (bonding-antibonding) interaction of lead atoms (showing numbering scheme for the NBO analysis). 
